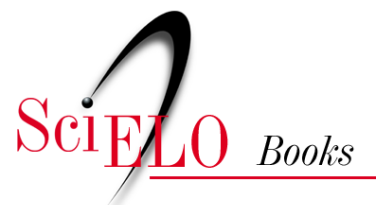

\title{
2 - Quando o patrimônio se movimenta: memória e identidade como estruturantes da ação coletiva
}

\author{
Aline Maria Matos Rocha
}

\section{SciELO Books / SciELO Livros / SciELO Libros}

ROCHA, A. M. M. Quando o patrimônio se movimenta: memória e identidade como estruturantes da ação coletiva. In: OLIVEIRA, G. M. C., and VIEIRA, K. M. A., eds. Patrimônio, povos do campo e memórias: diálogos com a cultura, a arte e a educação [online]. Mossoró: EdUFERSA, 2020, pp. 33-45. ISBN: 97865-87108-09-4. https://doi.org/10.7476/9786587108605.0003.

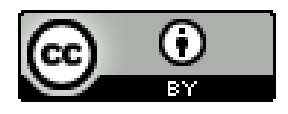

All the contents of this work, except where otherwise noted, is licensed under a Creative Commons Attribution 4.0 International license.

Todo o conteúdo deste trabalho, exceto quando houver ressalva, é publicado sob a licença Creative Commons Atribição 4.0. 


\section{QUANDO O PATRIMÔNIO SE MOVIMENTA: MEMÓRIA \\ E IDENTIDADE COMO \\ ESTRUTURANTES DA AÇÃO COLETIVA}

Aline Maria Matos Rocha

\section{Introdução}

A ação coletiva é a forma de atuação dos movimentos sociais. Tais ações buscam, muitas vezes, defender territórios, modos de vida e práticas socioculturais. Proponho tratar, nesta reflexão, a dimensão patrimonial como um dos elementos que contribui para estruturar a ação coletiva, quando esta volta seus objetivos, parciais ou integralmente, para a patrimonialização. Disputas que envolvem a defesa do patrimônio histórico, sob sua forma material ou imaterial, figuram como exemplares do fenômeno. O patrimônio e, por conseguinte, a memória e a identidade, são características que não só motivam a ação coletiva, mas lhe oferecem estrutura, dando sustentação à forma como os movimentos se organizam, se mantém e orientam sua ação na esfera pública. A ação coletiva, nesse âmbito, é uma ação organizada, por meio da qual um grupo de pessoas, entidades, instituições etc., age em conjunto, a fim de reivindicar direitos ou garantir sua efetividade.

Faz parte de minhas intenções situar a importância do caráter simbólico que orienta a ação dos movimentos sociais, tendo em vista a formação e construção do vínculo identitário - elemento também necessário à constituição das variadas manifestações do patrimônio. Espaço e território categorias e vetores ordinários no pensamento geográfico — são entendidos 
como condicionantes na formação identitária e levam à compreensão da dimensão simbólica dos movimentos sociais, principalmente quando se pensa na atuação articulada dos eixos memória, identidade e patrimônio.

Compreendo a ação coletiva em prol da patrimonialização como movimento que pode ser lido a partir da identificação dos aspectos culturais que envolvem formação, mobilização e manutenção dos movimentos sociais. Essa medida é tomada no momento em que é possível identificar que a noção de patrimônio histórico se estabelece, e este passa a ser importante campo de disputa, sobretudo a partir da segunda metade do século XX. Nesse momento, passa-se a reconhecer a relevância da preservação de uma memória coletiva, realçada não só por meio de edificações de diferentes tipologias, mas como práticas culturais, saberes e usos que funcionam como marcadores de diferença e identificação de grupos vinculados a territórios socioespaciais e simbólicos.

É com esse objetivo que minha reflexão encontra motivação, a fim de apontar o movimento pela patrimonialização enquanto espaço de disputa, o qual ajuda a definir o campo identitário de grupos implicados num confronto político ${ }^{1}$. Essas considerações não vêm isoladas de uma sensibilidade para as transformações conceituais e metodológicas por que passaram as teorias dos movimentos sociais, no âmbito de suas correntes sociológicas, principalmente quando a implicação da cultura ${ }^{2}$ e suas dimensões passa a ser algo relativamente recente no estudo da ação coletiva. São acrescidos, desde então, diferentes graus de complexidade ao seu entendimento, em meio às circunstâncias atuais de formação e organização dos movimentos.

Para tanto, procuro dar ênfase, a partir de uma exposição conceitual, à memória e à identidade como condicionantes que se articulam à definição de patrimônio, tornando-se categorias importantes para a formação e a manutenção da ação coletiva organizada. A partir de pesquisas empiricamente

1 O confronto político, para Tilly (1978), ocorre quando um conjunto de atores reivindica recursos valorizados por outro conjunto de atores, demarcando um espaço de disputa que envolverá mecanismos de organização e mobilização específicas, assim como assimétricas.

2 Ver Alonso (2009). 
sustentadas ${ }^{3}$, é fundamental responder como o vínculo com o lugar e suas práticas sociais podem motivar a formação de movimentos sociais, sendo úteis ao entendimento de suas manifestações, que podem atuar, articuladas ou isoladamente, às esferas do campo e da cidade.

\section{A dimensão cultural e simbólica da ação coletiva}

Sabe-se que o estudo da ação coletiva não é algo novo na teoria sociológica. Entretanto, só em fins do século XX, seu estudo passa a considerar e tematizar com maior ênfase e protagonismo sua dimensão cultural e, por conseguinte, simbólica, na explicação dos movimentos sociais. Alonso (2009, p. 77) conclui que, a partir dos anos 1990, a ênfase explicativa dos movimentos sociais desloca-se de forma permanente para a cultura e seus demais aspectos. Se entendermos prática cultural como "todas as formas de atividade social", assim como "modos de vida" e "sistemas de significações" (WILLIAMS, 1992), cabem aí as atuações que envolvem importantes campos de disputa, a partir dos quais se inserem os movimentos pela patrimonialização, em suas diversas escalas.

É com esse caráter mais amplo da noção de cultura que Peter Burns (2000, p. 86) também a compreende: "de forma a incluir uma variedade de comportamentos sociais e padrões como alimentação, 'espaço pessoal' etc. [...]. A cultura é a cola que mantém a sociedade coesa". Sem cair na armadilha de definir a cultura como "sendo tudo" ${ }^{4}$ Burns problematiza a categoria, o que permite conhecer com mais profundidade sua ordem complexa (BURNS, 2000, p. 75).

3 O tratamento conceitual de que falo é oriundo de uma pesquisa que tem como recorte empírico um movimento social urbano, em Fortaleza, CE, cujas frentes de luta também encampam a dimensão patrimonial. A pesquisa, em fase de finalização, é fruto do meu trabalho de doutoramento em Sociologia, pela Universidade Federal do Ceará (UFC).

4 Meneses (2012) reforça que a política de reconhecimento do chamado patrimônio imaterial, realizada pelo Instituto do Patrimônio Histórico e Artístico Nacional (IPHAN), entende o campo cultural como a totalidade da vida social. 
A definição de cultura, em si mesma, não conduz com clareza às explicações sobre a forma como os movimentos sociais atuam, se organizam ou defendem suas pautas. Importa extrair daí o aprendizado com o qual as lutas sociais vão incorporando seu modo de agir, a fim de reivindicar e exigir direitos. Práticas vividas e partilha de experiências em comum, elementos que permeiam a dimensão cultural, podem conduzir a uma compreensão mais ampla da ação coletiva e seus desdobramentos. No que tange à análise dos movimentos sociais, é fato que o enfoque às questões de ordem subjetiva, afetivas e culturais passam a entrar em cena no final do século XX, como implicações que orientarão a ação para o engajamento e o projeto emocional que envolve a ação dos sujeitos (ALEXANDER, 1998).

A produção de significado, por sua vez, leva a pensar no peso do simbólico nas vinculações sociais que conduzem a algum tipo de mobilização. Ruiz (2003) recupera o sentido da palavra symbolon que, em grego, remete à reunião de duas partes separadas, as quais, em si mesmas, não têm sentido algum, passando a adquirir sentido apenas quando se juntam. Conforme esclarece, "é a junção simbólica que confere o sentido pleno à realidade fraturada. O símbolo rejunta as partes separadas. O ser humano, ao conferir um sentido às coisas, realiza uma juntura simbólica com o mundo [...]" (RUIZ, 2003, p. 134, grifos do autor).

Entender a dimensão simbólica da ação coletiva está em buscar o sentido da ação, atribuído pelos agentes sociais que a praticam. Um movimento social está imbuído de muitas nuances de sentido. Quando se remete à luta por moradia e/ou disputas territoriais que se dão no meio urbano ou rural, várias "camadas" de significado e "junções simbólicas" operam. Associadas a falas que explicam a ação como: "quero permanecer no lugar em que nasci", "foi aqui que vivi todos os momentos da minha vida", "a gente também pode enfrentar gente rica" ${ }^{5}$, dentre outras, tem-se junções significativas e que dão tônus simbólico à luta instrumental-legal.

5 Falas recuperadas de entrevistas e observações realizadas com moradores organizados em prol do movimento social investigado. 
Ana Fani Carlos (2007) confirma o espaço geográfico como um produto histórico e social, meio em que as relações sociais, em sua concretude, estão ancoradas. É nesse sentido que as relações cotidianas, em seu tempo-espaço, são decisórias e condicionais na formação da identidade entre habitante e lugar. Pensar nos vínculos identitários constitui razão basilar para compreender processos de patrimonialização e sua defesa, uma vez que estes podem acionar, como geradores de diferença, o cotidiano e o espaço vivido, tomados como memória e modo de vida a ser preservado ${ }^{6}$.

Entende-se que o patrimônio é importante expressão da cultura e, enquanto tal, quando acionado por movimentos sociais, pode atuar como elemento estruturador da ação coletiva. Mas o que vem a ser o patrimônio? O que o constitui? Como os movimentos sociais lançam mão da memória e da identidade em sua formação e manutenção?

\section{Memória e identidade em ação: quando o patrimônio entra em cena}

Françoise Choay (2001) esclarece que a noção de patrimônio histórico alcançou significativa expressão e notoriedade pública e midiática a partir dos anos 1960. Ao questionar o que vem a ser o patrimônio histórico nas sociedades contemporâneas, Choay circunscreve sua abordagem às edificações, identificando a expansão do quadro cronológico e de espaços geográficos em que os bens considerados patrimoniais ou passíveis de patrimonialização se inscrevem. Após a $2^{\mathrm{a}}$ Guerra Mundial, assiste-se, em sua análise, a uma expansão de bens inventariados, dada a partir da identificação de variadas formas da arte de construir, consideradas eruditas ou populares, urbanas ou rurais, uma vez que "o domínio patrimonial não se limita mais aos edifícios

6 Essas características são marcas do que vem a ser o patrimônio imaterial. Para Meneses (2012), as manifestações do patrimônio cultural não podem ser entendidas sem considerar seus vetores materiais, isto é, todo patrimônio imaterial tem sua dimensão material, a qual oferece suporte para sua realização e reprodução, e vice-versa. Essas diferenças, segundo o autor, não são de natureza ontológica, mas operacionais. Reconhecer essa relação, despolariza as noções de patrimônio material e imaterial, cabendo situar no "saber-fazer" as marcas de um conhecimento sempre corporificado. 
individuais; ele agora compreende os aglomerados de edificações e a malha urbana: aglomerados de casas e bairros, aldeias, cidades inteiras e mesmo conjuntos de cidades" (CHOAY, 2001, p. 13).

Choay (2001) defende que o culto ao patrimônio histórico, contemporaneamente, rende mais do que uma "simples aprovação", devendo constituir-se como elemento revelador das condições em que se encerram a sociedade atual. Sua leitura está circunscrita à Paris e às matrizes do pensamento europeu quanto ao que deve ou não ser considerado expressão artístico-cultural válida para fins patrimoniais - fato que a autora adverte. Esses parâmetros eurocêntricos constituem, historicamente, um lastro da herança colonial que submeteu outras culturas e expressões ao seu jugo, demarcando uma "instância de legitimação"7 que imprimirá sua chancela ao que deve ou não ser inventariado.

Candau (2010, p. 44-45) denuncia um mnemotropismo massivo, definindo-o como devoção patrimonial compulsiva, a qual está relacionada à "irrupção espetacular da memória no debate público". Para o autor, cabe refletir sobre as bases antropológicas desse processo, pautado pelo que denomina de "inflação da memória" ou "bulimia patrimonial", os quais passam a conferir à patrimonialização o poder de restaurar vínculos e "vazios de sentido", trazendo como consequência uma objetificação demasiada da preservação e da própria busca patrimonial - situando casos europeus e norte-americanos ${ }^{8}$.

7 Ver Bourdieu $(2003,2007)$.

8 No Brasil, a busca patrimonial reverte-se em campo de disputa com representações que podem soar distintas das da Europa. Enquanto lá alega-se prolixidade de bens patrimonializados, aqui, os sentidos da preservação colocam-se na contramão de retóricas do desenvolvimento econômico, que passam a ocupar os ideais da estética urbana ou rural. É exemplar o movimento Ocupe Estelita, no Recife, cuja luta, ainda em vigor, agrega a defesa do patrimônio histórico da área em oposição à construção de 12 torres residenciais e comerciais que passariam a ocupar a paisagem do cais José Estelita (BUENO, 2014). Em menor escala, mas não menos significativo, em Fortaleza, uma praça seria demolida para dar lugar a um cruzamento. A Praça Portugal, localizada no bairro Aldeota, foi alvo de protestos em sua defesa e pedido de tombamento, que fora negado, por 12 votos contra e 7 a favor, em votação no Conselho Estadual de Patrimônio Cultural do Ceará (COEPA). A prefeitura 
Por outro lado, é certo haver consenso nas ciências sociais quanto à definição da identidade, largamente entendida como construção social marcada pela relação dialógica com o Outro. Candau (2010) pontua que a identidade não pode existir sem a memória, assim como não pode, inversamente, haver memória sem identidade. Memória e identidade, portanto, passam a caracterizar, condicionalmente, a definição de patrimônio, principalmente quando este, em especial nas sociedades contemporâneas, passa a agir como espécie de "aparelho ideológico da memória" (CANDAU, 2010, p. 44).

A memória é o modo pelo qual o passado se atualiza, tornando-se presente. Sua intrínseca relação com a identidade é demonstrada no momento em que "apelamos ao passado como fonte de identificação de pertencimento, ou seja: o que somos, como indivíduos ou grupos, depende de saber quem fomos e de onde viemos" (GONDIM, 2001, p. 176). Da mesma forma, Halbwachs (1990) entende que um grupo, ao considerar situações que envolvem seu passado, torna-se consciente de sua identidade através do tempo.

É importante para esta discussão destacar o sentido original do termo monumento. Do latim monumentum, a palavra encontra seu derivativo no termo monere, que significa lembrar. Sua origem associa-se àquilo que traz algo à lembrança, não podendo dissociar-se de seu caráter afetivo, uma vez que o núcleo de seu significado está em "tocar, pela emoção, uma memória viva" (CHOAY, 2001, p. 18).

O monumento, dessa maneira, revela seu modo de atuação sobre a memória, mobilizando-a por meio da afetividade. Mas não se trata da memória de um passado qualquer. Como reforça Choay (2001, p. 18), esse passado "é localizado e selecionado para fins vitais, na medida em que pode, de forma direta, contribuir para manter e preservar a identidade de uma comunidade étnica ou religiosa, nacional, tribal ou familiar". É nesse sentido que as definições daquilo que deve ou não ser lembrado, como e de que forma, constitui importante instrumento de disputa e de natureza substancialmente política.

de Fortaleza, mediante pressão da população, resolveu manter a praça, mas com modificações em seu perímetro (CONSELHO..., 2015; FIRMO, 2015). 
Devo destacar que o ato de lembrar, conforme Halbwachs (1990), vem acompanhado de uma condição que lhe é intrínseca: a interação social. Isso implica entender que os processos que envolvem o reconhecimento de um grupo e sua identidade encontram-se ancorados nas relações sociais, as quais podem lançar mão de recursos variados para acionar seu passado por meio de eventos e situações memoriais.

Por sua vez, manifestações da memória e, consecutivamente, da identidade, são passíveis de serem observadas por meio de indicadores empíricos fundados na experiência e que envolvem utilizações do espaço, assim como eventos que podem assumir um caráter ritualístico entre grupos que o vivenciam, tais como as comemorações (POLLAK, 1992). O mesmo autor conclui que a memória individual e a memória dos outros são passíveis de confronto, fazendo com que memória e identidade sejam valores sob disputa em conflitos sociais e, frequentemente, em conflitos que envolvem grupos políticos distintos.

O enfoque dessa discussão culmina na definição do patrimônio como dimensão da memória, sendo entendido também como "identidade em ação" (CANDAU, 2016). Faz-se necessário entender que as identidades não são objeto de nuanças estáveis e definidas objetivamente. Estas são produzidas e modificam-se continuamente dentro do "quadro das relações, reações e interações sociossituacionais - situações, contexto, circunstâncias - de onde emergem os sentimentos de pertencimento, de 'visões de mundo' identitárias ou étnicas" (CANDAU, 2016, p. 27).

Pollak (1992), por sua vez, indica três critérios empiricamente fundados como elementos constitutivos da memória individual ou coletiva: os acontecimentos, os personagens e os lugares. Os acontecimentos são demarcados por experiências no âmbito pessoal e que também se situam no interior de grupos, denominados pelo autor de "vividos por tabela"; os personagens são a identificação de que a memória constitui-se de pessoas, e estas atravessam nossa experiência no mundo; e, por último, os lugares demarcam o espaço em que se estabelecem as experiências de vida. Os três critérios não se restringem à existência cronológica do indivíduo, tendo em vista 
que tais situações também são objeto de "vivência" indireta, justamente acionada pelo contar e recontar, viver ou reviver, as práticas que demarcam a existência social de um grupo e, consequentemente, do indivíduo.

Em sentido semelhante, Candau (2016) define como interações sociossituacionais aquelas às quais vinculam-se as diferentes situações e circunstâncias em que se inscrevem as práticas sociais que operam como geradoras de diferença e que, a partir daí, auxiliam na produção dos sentidos de pertencimento, causadores do vínculo identitário.

Memória e identidade, portanto, arrematam a definição do patrimônio, formando um par conceitual condicionante de seu entendimento. Em sentido contíguo, os movimentos sociais resultam da articulação complexa de fatores, passando, ao mesmo tempo, pela definição interna de sua identidade enquanto grupo relativamente coeso e, a depender dos objetivos pretendidos, pela disputa externa em prol da patrimonialização, que pode ou não ser objeto de enfrentamento direto em sua causa.

\section{Patrimônio e ação coletiva: "a que será que se destina?"}

Para fins de conclusão, destaco que os movimentos sociais são investigados a partir de diferentes níveis de análise, que se empenha em identificar, internamente, seus processos de mobilização, suas formas organizativas, seus modelos de liderança, suas ideologias e formas de comunicação (MELUCCI, 2001).

Quando associado à luta pela patrimonialização, o movimento social dispõe, necessariamente, da memória e da identidade como elementos estruturantes de sua ação coletiva organizada. O caráter simbólico da ação coletiva atua, assim, em dupla camada: internamente, conformando os vínculos identitários e memoriais que o deverão compor e, externamente, por meio da busca patrimonial como bandeira de luta, ou seja, identidade e memória passam a ser reivindicativos da disputa e da presença do movimento numa arena pública.

É por esse motivo que o patrimônio é constitutivo de um fenômeno metamemorial (CANDAU, 2010). Uma vez vinculado a disputas políticas e econômicas, em meio a reprodução de uma visão hegemônica de espaço 
urbano ou rural, ele age como prática recursiva afirmativa, a fim de reivindicar a memória de um grupo e sua continuidade, no seio de uma esfera pública que poderá conferir-lhe algum poder.

A que será que se destina? O trecho da canção Cajuína ${ }^{9}$, de Caetano Veloso, oferece um desfecho significativo a esta reflexão, que buscou responder, de maneira provisória, como a busca pela patrimonialização, uma vez compondo a ação coletiva dos movimentos sociais, faz agir, de forma conjunta, a memória e a identidade como dimensões que constituem passado, presente e destino de uma sociedade.

9 Em tempo, a cajuína, bebida produzida a partir do caju, foi reconhecida como Patrimônio Cultural Brasileiro em 2014 (IPHAN, 2014). O registro autêntico a bebida e seus modos de produção e circulação como patrimônio cultural do estado do Piauí - de onde partiu o pedido. A bebida e sua produção encontram-se relacionada à cultura nordestina, fazendo-se presente em estados do nordeste brasileiro. 


\section{REFERÊNCIAS}

ALEXANDER, J. C. Ação Coletiva, Cultura e Sociedade Civil:

Secularização, atualização, inversão, revisão e deslocamento do modelo clássico dos movimentos sociais. Rev. bras. Ci. Soc., v. 13, n. 37, p. 5-31, jun. 1998. Disponível em: https://bit.ly/354BRkT. Acesso em 02 mar. 2020.

ALONSO, A. As Teorias dos movimentos sociais: um balanço do debate. Lua Nova, v. 76, p. 49-86, 2009. Disponível em: http://www.scielo.br/ pdf/ln/n76/n76a03.pdf. Acesso em: 21 out. 2018.

BOURDIEU, P. A Distinção: crítica social do julgamento. São Paulo: Edusp, 2007.

BOURDIEU, P. A Economia das trocas simbólicas. 5. ed. São Paulo: Perspectiva, 2003.

BUENO, C. Ocupe Estelita: movimento social e cultural defende marco histórico de Recife. Cienc. Cult., São Paulo, v. 66, n. 4, p. 6-7, dec. 2014. Disponível em: https://bit.ly/3hXCGjj. Acesso em: 07 mar. 2020.

BURNS, P. M. Turismo e antropologia: uma introdução. São Paulo: Chronos, 2002.

CARLOS, A. F. A. O Espaço urbano: novos escritos sobre a cidade. São Paulo: FFLCH, 2007.

CANDAU, J. Memória e identidade. São Paulo: Contexto, 2016. 
CANDAU, J. Bases antropológicas e expressões mundanas da busca patrimonial: memória, tradição e identidade. Revista Memória em Rede, v. 1, n. 1, dez. 2009. Disponível em: https://bit.ly/2EZGTo7. Acesso em: 21 jan. 2020.

CHOAY, F. A Alegoria do patrimônio. São Paulo: Unesp, 2001.

CONSELHO vota contra tombamento da Praça Portugal, em Fortaleza. G1, Fortaleza, 17 jun. 2015. Disponível em: http://glo.bo/1BiOciv. Acesso em: 07 mar. 2020.

FIRMO, É. Prefeitura define projeto que mantém Praça Portugal, na Aldeota. Jornal 0 Povo, Fortaleza, 05 nov. 2015. Disponível em: https://bit.ly/2QPsHk4. Acesso em: 05 mar. 2020.

GONDIM, L. M. P. A Construção social da memória na moderna Fortaleza. In: AGUIAR, O. A.; BATISTA, J. É.; PINHEIRO, J. (Org.). Olhares contemporâneos: cenas do mundo em discussão na Universidade. Fortaleza: Fundação Demócrito Rocha, 2001. p. 174-189. HALBWACHS, M. A Memória coletiva. São Paulo: Vértice, 1990. IPHAN-INSTITUTO DO PATRIMÔNIO HISTÓRICO E ARTÍSTICO NACIONAL. Cajuína do Piauí é mais novo Patrimônio Cultural Brasileiro. Rio de Janeiro: IPHAN, 2014. Disponível em: http://portal. iphan.gov.br/noticias/detalhes/286. Acesso em: 08 mar. 2020.

MELUCCI, A. A Invenção do presente: movimentos sociais nas sociedades complexas. Petrópolis: Vozes, 2001.

MENESES, U. T. B. O Campo do patrimônio cultural: uma revisão de premissas. In: FÓRUM NACIONAL DO PATRIMÔNIO CULTURAL, 1., 2009, Ouro Preto. Anais [...]. Brasília: IPHAN, 2012.

POLLAK, M. Memória e identidade social. Estudos históricos, Rio de Janeiro, v. 5, n. 10, p. 200-212, 1992.

POULOT, D. Uma história do patrimônio no Ocidente, séculos

XVIII-XIX: do monumento aos valores. São Paulo: Estação Liberdade, 2009. 
RUIZ, C. B. Os paradoxos do imaginário. São Leopoldo:

Unisinos, 2003.

TILLY, C. From mobilization to revolution. [S.l.]: Newberry Award Records, 1978.

WILLIAMS, R. Cultura. Rio de Janeiro: Paz e Terra, 1992. 